\title{
Electronic Properties and Dissociative Photoionization of Thiocyanates, Part III. The Effect of the Group's Electronegativity in the Valence and Shallow-Core (Sulfur and Chlorine 2p) Regions of $\mathrm{CCl}_{3} \mathrm{SCN}$ and $\mathrm{CCl}_{2} \mathrm{FSCN}$
}

Lucas S. Rodríguez Pirani, ${ }^{\dagger}$ Carlos O. Della Védova, ${ }^{*}{ }^{\dagger}{ }^{\circ}$ Mariana Geronés, $^{\dagger}$ Rosana M. Romano, $^{\dagger}$ Reinaldo Cavasso-Filho, ${ }^{\ddagger}$ Maofa Ge, ${ }^{\S}$ Chunping Ma, ${ }^{\S}$ and Mauricio F. Erben ${ }^{* \dagger \odot}$

†CEQUINOR (UNLP - CONICET, CCT La Plata), Departamento de Química, Facultad de Ciencias Exactas, Universidad Nacional de La Plata, Boulevard 120 e/60 y 64 No. 1465, La Plata CP 1900, República Argentina

†Universidade Federal do ABC, Rua Catequese, 242, CEP 09090-400 Santo André, São Paulo, Brazil

${ }^{\S}$ State Key Laboratory for Structural Chemistry of Unstable and Stable Species, Beijing National Laboratory for Molecular Sciences (BNLMS), Institute of Chemistry, Chinese Academy of Sciences, Beijing 100190, Peoples Republic of China

\section{Supporting Information}

\begin{abstract}
Both photoelectron spectroscopy (PES) data and PhotoElectron-PhotoIon-Coincidence (PEPICO) spectra obtained from a synchrotron facility have been used to examine the electronic structure and the dissociative ionization of halomethyl thiocyantes in the valence and shallow-core $\mathrm{S} 2 \mathrm{p}$ and $\mathrm{Cl} 2 \mathrm{p}$ regions. Two simple and closely related molecules, namely, $\mathrm{CCl}_{3} \mathrm{SCN}$ and $\mathrm{CCl}_{2} \mathrm{FSCN}$, have been analyzed to assess the role of halogen substitution in the electronic properties of thiocyanates. The assignment of the $\mathrm{He}(\mathrm{I})$ photoelectron spectra has been achieved with the help of quantum chemical calculations at the outer-valence Green's function (OVGF) level of approximation. The first ionization energies observed at 10.55 and $10.78 \mathrm{eV}$ for $\mathrm{CCl}_{3} \mathrm{SCN}$ and $\mathrm{CCl}_{2} \mathrm{FSCN}$, respectively, are assigned to ionization

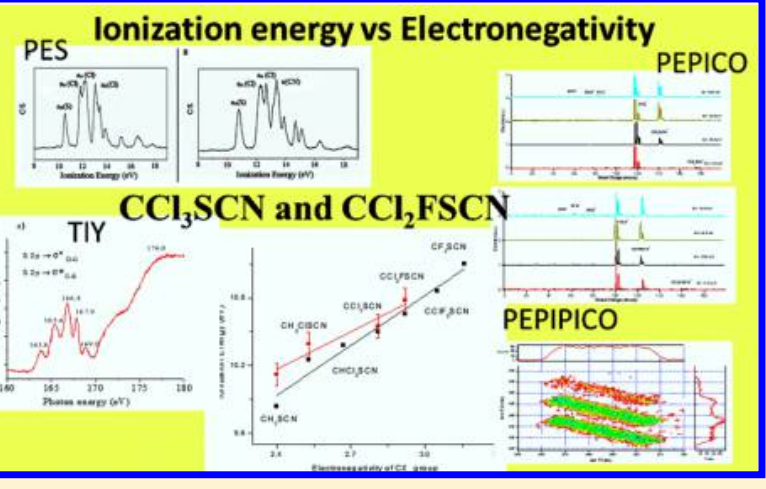
processes from the sulfur lone pair orbital $[\mathrm{n}(\mathrm{S})]$. When these molecules are compared with $\mathrm{CX}_{3} \mathrm{SCN}(\mathrm{X}=\mathrm{H}, \mathrm{Cl}, \mathrm{F})$ species, a linear relationship between the vertical first ionization energy and electronegativity of $\mathrm{CX}_{3}$ group is observed. Irradiation of $\mathrm{CCl}_{3} \mathrm{SCN}$ and $\mathrm{CCl}_{2} \mathrm{FSCN}$ with photons in the valence energy regions leads to the formation of $\mathrm{CCl}_{2} \mathrm{X}^{+}$and $\mathrm{CClXSCN}^{+}$ions $(\mathrm{X}$ $=\mathrm{Cl}$ or $\mathrm{F}$ ). Additionally, the achievement of the fragmentation patterns and the total ion yield spectra obtained from the $\mathrm{PEPICO}$ data in the $\mathrm{S} 2 \mathrm{p}$ and $\mathrm{Cl} 2 \mathrm{p}$ regions and several dissociation channels can be inferred for the core-excited species by using the triple coincidence PEPIPICO (PhotoElectron-PhotoIon-PhotoIon-Coincidence) spectra.
\end{abstract}

\section{INTRODUCTION}

The interest of haloalkyl thiocyanates is very much extended in the organic chemistry. They are used as key intermediates to

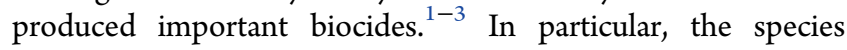
chloromethyl thiocyanate, $\mathrm{CH}_{2} \mathrm{ClSCN}$, shows a wide activity as fungicide, nematocide, and bactericide. The production of the fungicide 2-(thiocyanomethylthio)-benzothiazole, used in the leather industry, uses also this intermediate. ${ }^{4,5}$ It is known that $\mathrm{CCl}_{3} \mathrm{SCN}$ displays biological activity as an agent to control certain insect pests. ${ }^{6,7}$

Taking into account the singular importance of these kinds of molecules, few spectroscopic data have been reported. The infrared and Raman spectra of both $\mathrm{CCl}_{3} \mathrm{SCN}$ and $\mathrm{CCl}_{2} \mathrm{FSCN}$ molecules have been interpreted in terms of $C_{s}$ and $C_{1}$ molecular symmetry, respectively. ${ }^{8,9}$ Recently, the title molecules have been structurally studied in both gas and crystal phases by means of gas electron diffraction (GED) and low-temperature single-crystal X-ray diffraction (XRD)..$^{10,11}$ The experimental results concluded that the crystal structure of $\mathrm{CCl}_{2}$ FSCN contains solely the gauche-conformer (FC-SC dihedral angle near to $60^{\circ}$ ) while in the gas phase both gaucheand anti-conformations (FC-SC dihedral angle near to $180^{\circ}$ ) are present in equilibrium at room temperature, with the gauche-conformer being the most stable form. On the other hand, the crystal and gas phase conformations of the $\mathrm{CCl}_{3} \mathrm{SCN}$ molecule show that the $\mathrm{CCl}_{3}$ group results staggered with respect to the SCN group.

Electronic properties for the simple $\mathrm{CH}_{3} \mathrm{SCN}$ derivative were previously studied by Hitchcock et al. ${ }^{12}$ More recently, our group has investigated the ionic dissociation of $\mathrm{CH}_{3} \mathrm{SCN}^{13}$ and

Received: August 25, 2017

Revised: November 2, 2017

Published: November 2, 2017 


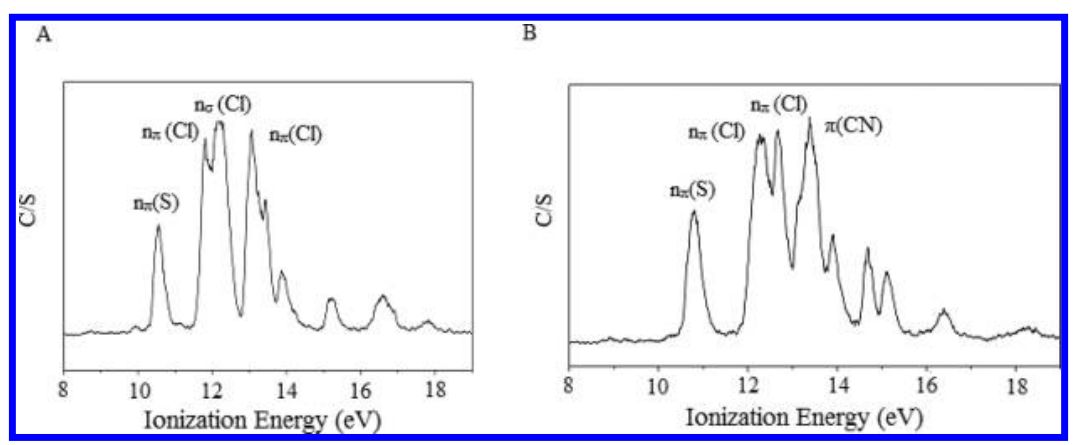

Figure 1. HeI photoelectron spectra of $\mathrm{CCl}_{3} \mathrm{SCN}$ (a) and $\mathrm{CCl}_{2} \mathrm{FSCN}(\mathrm{b})$.

$\mathrm{CH}_{2} \mathrm{ClSCN}^{14}$ molecules induced by photon impact excitation at the $\mathrm{S} 2 \mathrm{p}$ and $\mathrm{Cl} 2 \mathrm{p}$ levels and the dissociation dynamics was determined by using synchrotron radiation and multicoincidence techniques. In both species, the HOMO corresponds to $\mathrm{n}_{\pi}(\mathrm{S})$ lone pair electrons and the fragmentation dynamics is dominated by the rupture of the $\mathrm{C}-\mathrm{S}$ bond.

Herein, and as part of a general project aimed to elucidate the electronic properties of thiocyanates compounds by using synchrotron radiation in combination with photoelectron spectroscopy, we present a study of two closely related molecules, i.e., $\mathrm{CCl}_{3} \mathrm{SCN}$ and $\mathrm{CCl}_{2} \mathrm{FSCN}$, in the 11.2 and $300.0 \mathrm{eV}$ photon energy range. Outermost valence electrons as well as $\mathrm{S} 2 \mathrm{p}$ and $\mathrm{Cl} 2 \mathrm{p}$ shallow-core electrons were excited, and the positive ions formed after ionization were detected by means of coincidence techniques.

\section{EXPERIMENTAL SECTION}

As already described earlier, ${ }^{13,14}$ we have used the facilities kindly offered at the Laboratório Nacional de Luz Síncrotron (LNLS), Campinas, São Paulo, Brazil, to use synchrotron radiation. ${ }^{15}$ The toroidal grating monochromator TGM, which is operative in the range between $11.2-300 \mathrm{eV}$, offers linearly polarized light interacting with the sample inside a high-vacuum chamber kept with a pressure of ca. $10^{-8}$ mbar. $^{16}$

The fwhm of the light beam was determined to be $1 \mathrm{~mm} .^{17}$ The pressure of the sample was maintained below $5 \times 10^{-6}$ mbar during the measurements. A resolution power better than 400 can be achieved in the TGM beamline under these conditions. The well-known $S 2 p \rightarrow 6 a_{1 g}$ and $S 2 p \rightarrow 2 t_{2 g}$ signals of $\mathrm{SF}_{6}$ were used to calibrate the energies. ${ }^{18}$

The use of a gas-phase harmonic filter in the $11.2-21.5 \mathrm{eV}$ region allowed the provision of high-purity vacuum-ultraviolet photons due to the removal of contamination by high-order harmonics. ${ }^{19-21}$ The intensity of the emergent beam was recorded with a light-sensitive diode. The ions produced when the synchrotron light interacts with the sample were detected using a time-of-flight (TOF) mass spectrometer of the WileyMcLaren type for both PhotoElectron-PhotoIon-Coincidence (PEPICO) and PhotoElectron-PhotoIon-PhotoIon-Coincidence (PEPIPICO) experiments. ${ }^{22-24}$ The characteristics and performance of this electron-ion coincidence TOF spectrometer have been already reported. ${ }^{17}$

The average kinetic energy release (KER) values of the fragments have been deduced from the coincidence spectra by assuming both an isotropic distribution of the fragments, that they are perfectly space focused and that the electric field applied in the extraction region is uniform. ${ }^{25}$ Thus, the peak width contains the information to determine the energy release in the fragmentation processes. ${ }^{26}$ When the ideal conditions are not fully obtained an increase of the peak width is observed. A peak width of $0.05 \mathrm{eV}$ was obtained for the $\mathrm{Ar}^{+}$ion during the measurements of the argon mass spectrum under very similar experimental conditions. ${ }^{27}$ Thus, this value constitutes a reliable estimation for the instrumental resolution since this broadening in $\mathrm{Ar}^{+}$can be originated from thermal energy and instrumental broadening.

The experimental conditions to determine the $\mathrm{HeI} \mathrm{PE}$ spectra of $\mathrm{CCl}_{3} \mathrm{SCN}$ and $\mathrm{CCl}_{2} \mathrm{FSCN}$ have been already reported. A resolution of about $30 \mathrm{meV}$ can be deduced as indicated by the $\operatorname{Ar}^{+}\left({ }^{2} \mathrm{P}_{3 / 2}\right)$ photoelectron band. ${ }^{28-30}$ The calibration of the vertical ionization energies was made by addition of small portions of argon and iodomethane to the sample.

OVGF calculations using the cc-pVTZ basis set and MP2/ccpVTZ optimized geometries of $\mathrm{CCl}_{3} \mathrm{SCN}$ and $\mathrm{CCl}_{2} \mathrm{FSCN}$ have been computed using the Gaussian 03 program suit. ${ }^{31}$

The samples of $\mathrm{CCl}_{3} \mathrm{SCN}$ and $\mathrm{CCl}_{2} \mathrm{FSCN}$ were obtained from the following reactions. ${ }^{32,33}$

$\mathrm{CCl}_{3} \mathrm{SCN}$ :

$$
\mathrm{CCl}_{3} \mathrm{SCl}+\mathrm{AgCN} \rightarrow \mathrm{CCl}_{3} \mathrm{SCN}+\mathrm{AgCl}
$$

$\mathrm{CCl}_{2} \mathrm{FSCN}$ :

$$
\begin{gathered}
\mathrm{CCl}_{3} \mathrm{SCl}+\mathrm{HF} \rightarrow \mathrm{CCl}_{2} \mathrm{FSCl}+\mathrm{HCl} \\
\mathrm{CCl}_{2} \mathrm{FSCl}+\mathrm{AgCN} \rightarrow \mathrm{CCl}_{2} \mathrm{FSCN}+\mathrm{AgCl}
\end{gathered}
$$

The liquid samples were purified by several trap-to-trap vacuum distillations. The purity of the compounds was measured by FTIR spectroscopy.

\section{RESULTS AND DISCUSSION}

3.1. Photoelectron Spectra. The HeI photoelectron (PE) spectra of $\mathrm{CCl}_{3} \mathrm{SCN}$ and $\mathrm{CCl}_{2} \mathrm{FSCN}$ are shown in Figure 1 . The experimental and computed (OVGF/cc-pVTZ) vertical ionization energies can be shown in Table 1 .

The molecular conformation of a molecule results decisive to derive its ionization energies ${ }^{34,35}$ The $\mathrm{CCl}_{3} \mathrm{SCN}$ molecule shows only one stable form in the gas phase, the gauche conformer. ${ }^{10} \mathrm{CCl}_{2} \mathrm{FSCN}$ presents both gauche- and anticonformations in equilibrium at ambient temperature, with the gauche-rotamer being the most stable. ${ }^{11}$ Thus, ionization values have been computed for both conformers, as shown in Table 1. Similar ionization values were computed for both forms being the same the characters deduced for the molecular orbitals. The characters of the highest occupied molecular orbitals for $\mathrm{CCl}_{3} \mathrm{SCN}$ and for the most stable rotamer of $\mathrm{CCl}_{2} \mathrm{FSCN}$ are shown in Figure 2. In the electronic ground state, the $\mathrm{CCl}_{3} \mathrm{SCN}$ species belongs to the $C_{S}$ point group of 
Table 1. Experimental and Computed Ionization Energies (OVGF/cc-pVTZ, in eV) and MO Characters for $\mathrm{CCl}_{3} \mathrm{SCN}$ and $\mathrm{CCl}_{2}$ FSCN Molecules

\begin{tabular}{|c|c|c|c|c|c|}
\hline \multirow{2}{*}{\multicolumn{2}{|c|}{$\mathrm{CCl}_{3} \mathrm{SCN}$}} & \multicolumn{3}{|c|}{$\mathrm{CCl}_{2} \mathrm{FSCN}$} & \multirow[b]{3}{*}{ character } \\
\hline & & \multirow[b]{2}{*}{ exptl } & \multicolumn{2}{|c|}{ calcd $(\mathrm{eV})$} & \\
\hline exptl & calcd $(\mathrm{eV})$ & & gauche & anti & \\
\hline 10.55 & 10.50 & 10.78 & 10.70 & 10.73 & $\mathrm{n}_{\pi}(\mathrm{S})$ \\
\hline 11.80 & 11.76 & 12.24 & 11.97 & 12.22 & $\mathrm{n}_{\pi}(\mathrm{Cl})$ \\
\hline \multirow[t]{3}{*}{12.18} & 11.99 & & 12.29 & 12.26 & $\mathrm{n}_{\sigma}(\mathrm{Cl})$ \\
\hline & 12.18 & & & & $\mathrm{n}_{\sigma}(\mathrm{Cl})$ \\
\hline & 12.20 & & & & $\mathrm{n}_{\sigma}(\mathrm{Cl})$ \\
\hline \multirow[t]{2}{*}{13.05} & 13.05 & 12.67 & 12.38 & 12.67 & $\mathrm{n}_{\pi}(\mathrm{Cl})$ \\
\hline & 13.10 & & 12.99 & 13.07 & $\mathrm{n}_{\sigma}(\mathrm{Cl})$ \\
\hline 13.43 & 13.15 & 13.38 & 13.28 & 13.55 & $\pi(\mathrm{CN})$ \\
\hline \multirow[t]{3}{*}{13.88} & 14.07 & 13.92 & 13.93 & 14.14 & $\pi(\mathrm{CN})$ \\
\hline & & 14.80 & 14.27 & 14.40 & $\mathrm{n}_{\sigma}(\mathrm{F})$ \\
\hline & & 15.10 & 15.25 & 15.39 & $\mathrm{n}_{\sigma}(\mathrm{F})$ \\
\hline \multicolumn{2}{|c|}{$\mathrm{CCl}_{3} \mathrm{SCN}$} & $\mathrm{CCl}_{2}$ & & \multicolumn{2}{|c|}{ Characters } \\
\hline & & & & \multicolumn{2}{|c|}{$\mathrm{HOMO}, \mathrm{n}_{\pi}(\mathrm{S})$} \\
\hline & & & & \multicolumn{2}{|c|}{$\mathrm{HOMO}-1, \mathrm{n}_{\pi}(\mathrm{Cl})$} \\
\hline & & & & \multicolumn{2}{|c|}{$\mathrm{HOMO}-2, \mathrm{n}_{0}(\mathrm{Cl})$} \\
\hline \multicolumn{2}{|c|}{80} & & & \multicolumn{2}{|c|}{$\begin{array}{c}\mathrm{HOMO}-7, \pi(\mathrm{CN}) \\
\left(\mathrm{CCl}_{3} \mathrm{SCN}\right) \\
\mathrm{HOMO}-5, \pi(\mathrm{CN}) \\
\left(\mathrm{CCl}_{2} \mathrm{FSCN}\right)\end{array}$} \\
\hline
\end{tabular}

Figure 2. Characters of the main occupied valence orbitals of the $\mathrm{CCl}_{3} \mathrm{SCN}$ and $\mathrm{CCl}_{2} \mathrm{FSCN}$ molecules.

symmetry. Then, for further reference, all canonical molecular orbitals of type a' are $\sigma$ orbitals lying in the molecular plane, whereas those of type $\mathrm{a}^{\prime \prime}$ are $\pi$ orbitals.

The first ionization bands for the $\mathrm{CCl}_{3} \mathrm{SCN}$ and $\mathrm{CCl}_{2} \mathrm{FSCN}$ molecules appearing in the spectra at 10.55 and $10.78 \mathrm{eV}$, respectively, are assigned with confidence to the ionization process from the sulfur lone pair orbital $\left[n_{\pi}(S)\right]$ (see Figure 2), in good agreement the first ionization energy reported for the closely related $\mathrm{CH}_{3} \mathrm{SCN}$ analogue $\mathrm{e}^{36,37}$ and thiocyanate species. $^{38}$

For $\mathrm{CCl}_{3} \mathrm{SCN}$, a band located at around $11.80 \mathrm{eV}$ and the following two signals centered at 12.18 and $13.05 \mathrm{eV}$ are related to the electron ionization of chlorine lone pair orbitals $[\mathrm{n}(\mathrm{Cl})]$. In the case of $\mathrm{CCl}_{2} \mathrm{FSCN}$, the ionization processes caused by an electron ejected for the chlorine lone pair orbitals are associated with the bands observed at 12.24 and $12.67 \mathrm{eV}$. The 13.43 and $13.38 \mathrm{eV}$ features in the PES of $\mathrm{CCl}_{3} \mathrm{SCN}$ and $\mathrm{CCl}_{2} \mathrm{FSCN}$, respectively, are connected to an ionization event from the thiocyanate group, $\pi(\mathrm{CN})$. These bands are rather broad, probably due to the effect of populating several vibrationally excited ionic states associated with the $\nu(\mathrm{C} \equiv \mathrm{N})$ stretching mode, with typical values of ca. $2150 \mathrm{~cm}^{-1}$ for neutral thiocyanates. 39
3.2. Correlation between Group Electronegativity and Ionization Energy. When the photoelectron spectra of the title molecules are compared with related species, such as $\mathrm{CH}_{3} \mathrm{SCN}^{36}$ and $\mathrm{CH}_{2} \mathrm{ClSCN},{ }^{14}$ a dependency of the vertical ionization energy with the electronegativity of the $-\mathrm{CX}_{3}(\mathrm{X}=$ $\mathrm{H}, \mathrm{Cl}, \mathrm{F}$ ) group is observed. The concept of electronegativity is well established in chemistry. It refers to the capacity of an atom (or functional group) to attract electrons to itself. Linus Pauling defined this concept as "the power of an atom in a molecule to attract electrons to itself". ${ }^{40}$ Then, the extension of this concept to groups of atoms gave rise to group electronegativity, in which a functional group can be treated as a pseudoatom. Hardness represents another related concept. It has been defined to be half the derivative of electronegativity with respect to charge. ${ }^{41}$ Hardness is a property inversely related to polarizability. ${ }^{42,43} \mathrm{~A}$ charge distribution in a molecule (the electronegativity of its component atoms) and its polarizability (the hardness of the component atoms) govern the inner-shell ionization energies. Therefore, the correlation between the core-ionization energy of a central atom and the electronegativity sum of the substituents attached to the atom can be expected. Thomas et al. ${ }^{44}$ have shown that both electronegativity and hardness are very much related with the ionization energies in a previous report over halomethanes.

The family of the molecules studied in this work, the halomethyl thiocyanates, are also good candidates for this determination. Whereas in this series the molecules present basically similar structures and bonding, the electronegativities and polarizabilities of the $-\mathrm{CX}_{3}(\mathrm{X}=\mathrm{H}, \mathrm{Cl}, \mathrm{F})$ group, however, vary over a wide range depending on the kind and number of halogen atoms which are present in the molecule. These changes in the electronegativity of group attached to the sulfur atom affect directly to the firsts ionization energy of these compounds, since it is associated with the ionization process starting at the $\pi$ lone pair orbital localized on the $S$ atom.

Figure 3 shows the experimental and theoretical vertical ionization energies of $\mathrm{CX}_{3} \mathrm{SCN}$ species as a function of the

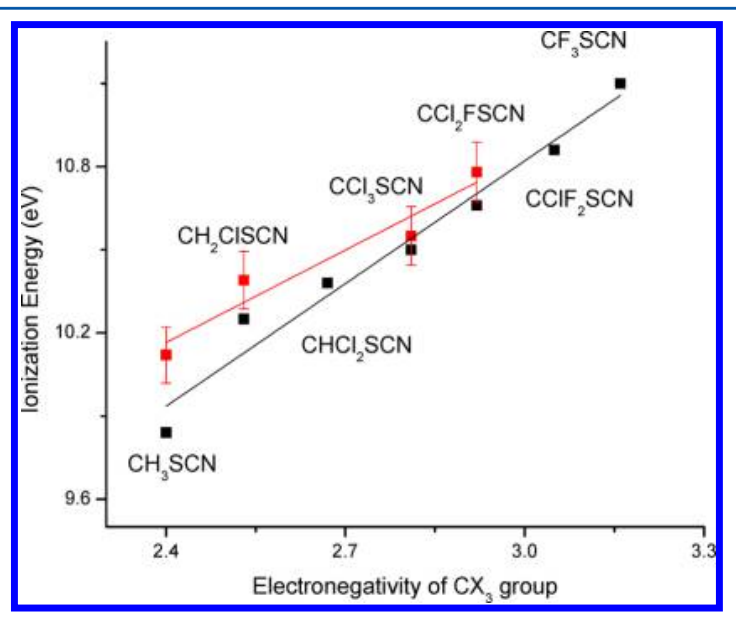

Figure 3. Experimental (red) and theoretical (black) vertical ionization energies of $\mathrm{CX}_{3} \mathrm{SCN}(\mathrm{X}=\mathrm{H}, \mathrm{F}, \mathrm{Cl})$ molecules as a function of the electronegative of $\mathrm{CX}_{3}$ group.

electronegative of the $\mathrm{CX}_{3}$ group, with $\mathrm{X}=\mathrm{H}, \mathrm{F}$, and $\mathrm{Cl}$. Taking the methyl derivative, i.e. $\mathrm{CH}_{3} \mathrm{SCN}$, as a reference, it is observe that the substitution of the hydrogen by fluorine and chlorine atoms cause an increment of the electronegative of this 


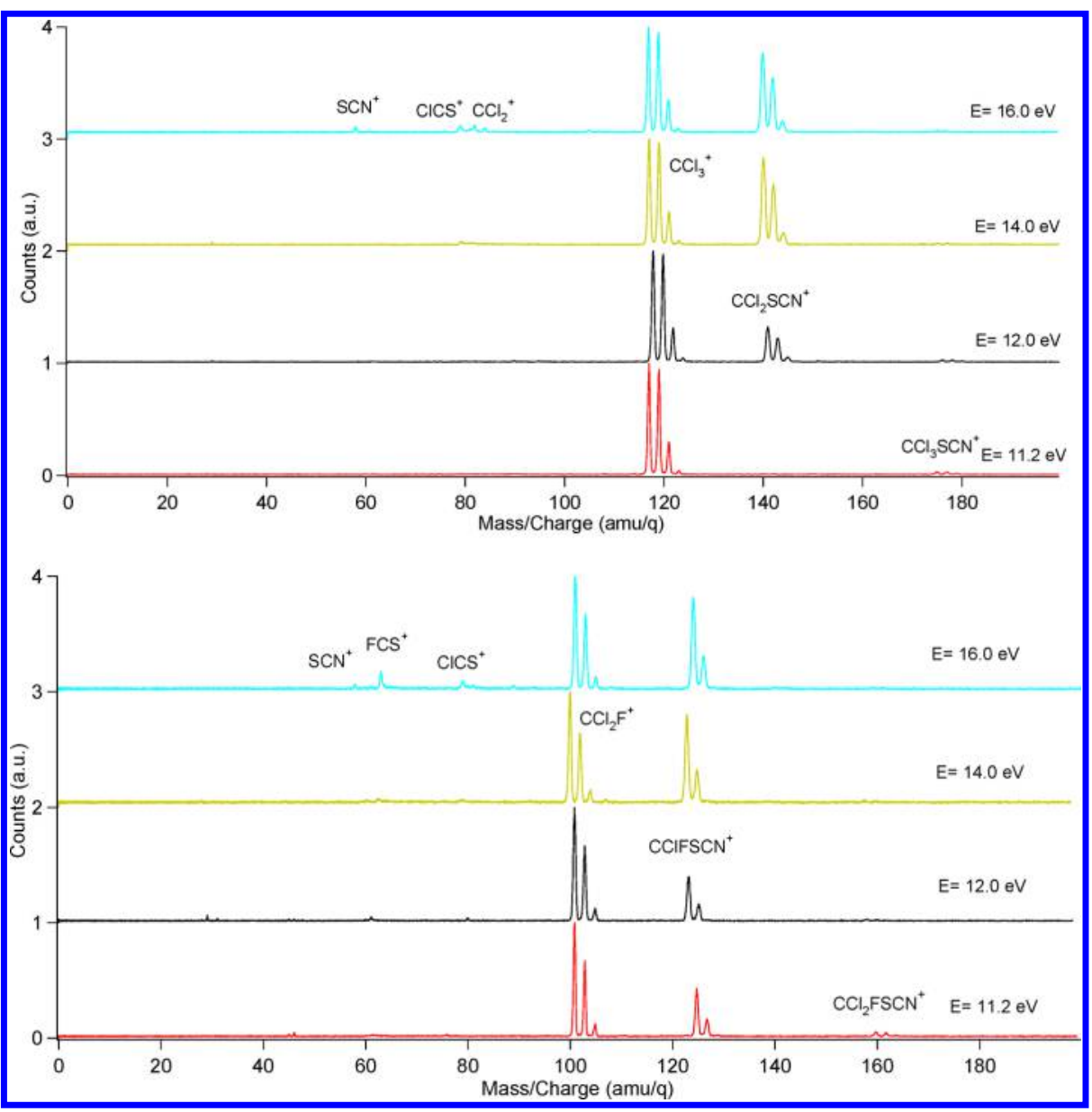

Figure 4. PEPICO spectra of $\mathrm{CCl}_{3} \mathrm{SCN}$ (left panel) and $\mathrm{CCl}_{2} \mathrm{FSCN}$ (right panel) at selected energies into the valence regions.

group in agreement with the electron-withdrawing property of halogens, leading to higher first ionization energy values.

A molecular orbital diagram for a series of $\mathrm{CX}_{3} \mathrm{SCN}$ molecules is depicted in Figure S1 (Supporting Information). The formal change of the hydrogen atom by more electronegative groups is related to higher energy potential values for the valence electrons. Therefore, the $\mathrm{CF}_{3} \mathrm{SCN}$ species presents a higher stabilization of both the $\mathrm{n}_{\pi}(\mathrm{S})$ and $\pi(\mathrm{CN})$ orbitals.

3.3. Photoionization in the Valence Region. The title compounds were irradiated with synchrotron monochromatic light in the energy region extended between 11.2 and $21.0 \mathrm{eV}$. Simultaneously, the electrons and cationic fragments produced upon photoionization and eventually subsequent fragmentation events were collected in coincidence, and PEPICO spectra were taken.

The coincidence spectra for both $\mathrm{CCl}_{3} \mathrm{SCN}$ and $\mathrm{CCl}_{2} \mathrm{FSCN}$ irradiated in this energy range are shown in the Figure 4 . In Table 2, the branching ratios for ion production are also listed. When photons with $11.2 \mathrm{eV}$ are used (the lower energy delivered by the TGM line when experiments were performed) very simple spectra are obtained. This value of energy is higher than the first ionization potential of these molecules (10.55 and $10.78 \mathrm{eV}$ for $\mathrm{CCl}_{3} \mathrm{SCN}$ and $\mathrm{CCl}_{2} \mathrm{FSCN}$, respectively), being possible to observe in these spectra ionization processes starting from the HOMO, corresponding to $n_{\pi}(S)$ lone pair electrons formally located on the sulfur atoms.

In both cases, the single charged molecular ion is detected with low intensity and the PEPICO spectra measured are dominated by only two intense signals in all range of energy.
Table 2. Branching Ratios (\%) for Fragment Ions Extracted from PEPICO Spectra Taken at Photon Energies into the Valence Regions for $\mathrm{CCl}_{3} \mathrm{SCN}$ and $\mathrm{CCl}_{2} \mathrm{FSCN}$ Molecules ${ }^{a}$

\begin{tabular}{llcccc} 
& & \multicolumn{4}{c}{ photon energy $(\mathrm{eV})$} \\
\cline { 3 - 6 }$m / z$ & \multicolumn{1}{c}{ ion } & 11.2 & 12.0 & 14.0 & 16.0 \\
$\mathrm{nnCl}{ }_{3} \mathrm{SCN}$ & & & & & \\
58 & $\mathrm{SCN}^{+}$ & & & & 3.2 \\
79 & $\mathrm{ClCS}^{+}$ & & & & 7.6 \\
82 & $\mathrm{CCl}_{2}^{+}$ & & & & 7.4 \\
117 & $\mathrm{CCl}_{3}^{+}$ & 93.9 & 74.5 & 55.0 & 46.5 \\
140 & $\mathrm{CCl}_{2} \mathrm{SCN}^{+}$ & & 25.5 & 45.0 & 35.3 \\
175 & $\mathrm{CCl}_{3} \mathrm{SCN}^{+}$ & 6.1 & - & & \\
$\mathrm{CCl}$ & & & & & \\
58 & $\mathrm{SCN}^{+}$ & & & & 3.5 \\
63 & $\mathrm{FCS}^{+}$ & & & & 7.9 \\
79 & $\mathrm{ClCS}^{+}$ & & & & 9.8 \\
101 & $\mathrm{CCl}_{2} \mathrm{~F}^{+}$ & 64.2 & 68.6 & 56.4 & 44.9 \\
124 & $\mathrm{CClFSCN}^{+}$ & 28.5 & 31.4 & 43.6 & 33.9 \\
159 & $\mathrm{CCl}_{2} \mathrm{FSCN}^{+}$ & 7.35 & & - & -
\end{tabular}

${ }^{a}$ Contributions of the $35 / 37$ natural isotopologues of $\mathrm{Cl}$ were summed together.

The main photodissociation channel is produced for the rupture of the sulfur-carbon single bond from $\mathrm{CCl}_{2} \mathrm{XSCN}^{+}(\mathrm{X}$ $=\mathrm{Cl}$ or $\mathrm{F}$ ) species (see Scheme 1), leading to the formation of $\mathrm{CCl}_{3}{ }^{+}(117 \mathrm{amu} / \mathrm{q})$ and $\mathrm{CCl}_{2} \mathrm{~F}^{+}$(101 aum/q), respectively.

The second ionic contribution is the loss of one $\mathrm{Cl}$ atom from the single charged molecular ion $\left(\mathrm{M}^{+}-35\right)$, resulting in 
Scheme 1

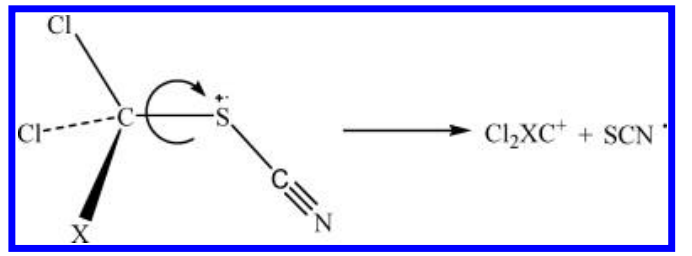

the formation of $\mathrm{CClXSCN}^{+}(\mathrm{X}=\mathrm{Cl}$ or $\mathrm{F})$ species. These ions can be characterized as derived from the parent ion by rupture of the $\mathrm{C}-\mathrm{Cl}$ bond, with the charge being retained in the molecular fragment (see Scheme 2). Naturally occurring isotopic contributions are plainly resolved, giving confidence to this assignment.

\section{Scheme 2}

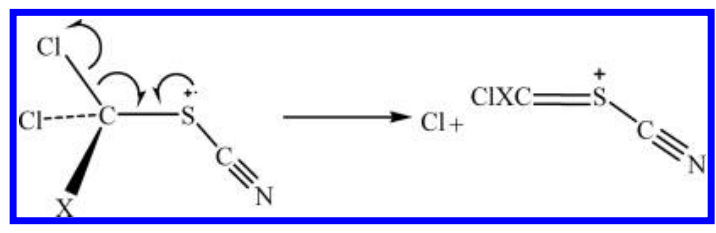

When the samples are irradiated with photon energies higher than $14.0 \mathrm{eV}$, the observation of ionization fragmentation channels for the production of the ions $\mathrm{XCS}^{+}(\mathrm{X}=\mathrm{Cl}$ or $\mathrm{F})$ and $\mathrm{SCN}^{+}$from ionized states of $\mathrm{CCl}_{3} \mathrm{SCN}$ and $\mathrm{CCl}_{2} \mathrm{FSCN}$ becomes possible. In the case of $\mathrm{CCl}_{3} \mathrm{SCN}$, the ionization channel process for the formation of $\mathrm{CCl}_{2}^{+}$is opened at a photon energy near $16.0 \mathrm{eV}$.

3.4. Total Ion Yield Spectra (TIY). When the parent and fragment ions are detected with different incident photon energy a complement to the information gained from absorption spectroscopy is reached. ${ }^{45}$ The TIY spectra of $\mathrm{CCl}_{3} \mathrm{SCN}$ and $\mathrm{CCl}_{2}$ FSCN between 160.0 and $180.0 \mathrm{eV}$ depicted in the Figure 5 were obtained in the region near the $S 2 p$ edge by recording the count rates of the total ions.

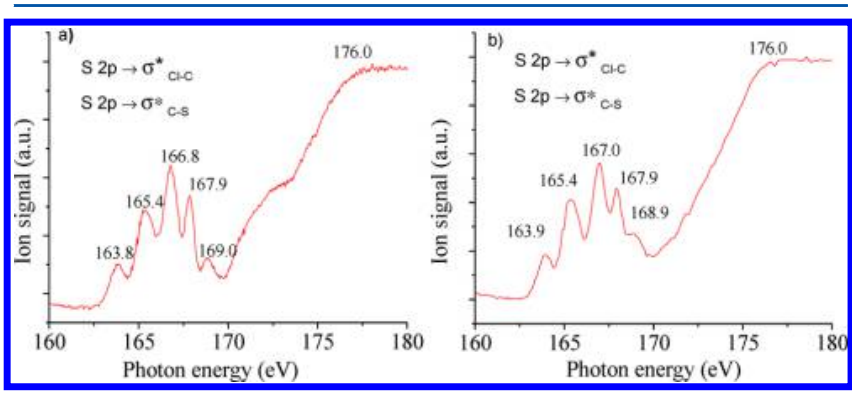

Figure 5. Total ion yield spectra for $\mathrm{CCl}_{3} \mathrm{SCN}$ (a) and $\mathrm{CCl}_{2} \mathrm{FSCN}$ (b) near the $S 2 p$ edge.

A group of well-defined features in the region below the $S 2 p$ ionization threshold ranged between 164.0 and $169.0 \mathrm{eV}$ has been clearly observed in TIY spectra. These features should be originated from processes involving permitted transitions between the $S 2 p$ electron and an antibonding molecular orbital. Following the proposed assignment for $\mathrm{S} 2 \mathrm{p}$ transitions for both $\mathrm{CH}_{3} \mathrm{SCN}^{12}$ and $\mathrm{CH}_{2} \mathrm{ClSCN}^{14}$ in which the most relevant signals were attributed to states related with $(S 2 p$, $\left.\pi_{\mathrm{SCN}}^{*}\right)$ and (S 2p, $\sigma^{*}{ }_{\mathrm{CS}}$ ) electronic configurations, the clear observed structures in the TIY spectra can be due to electronic transitions involving the spin-orbit split of the $2 \mathrm{p}$ sulfur excited species $\left(2 \mathrm{p}_{1 / 2}\right.$ and $2 \mathrm{p}_{3 / 2}$ levels $)$ to unoccupied orbitals, mainly the LUMO $\left(\sigma^{*}{ }_{\mathrm{Cl}-\mathrm{C}}\right)$ and LUMO+1 $\left(\sigma^{*}{ }_{\mathrm{C}-\mathrm{S}}\right)$ antibonding orbitals, in accordance with the calculated characters for the first unoccupied molecular orbitals displayed in Figure S2 (Supporting Information).

TIY spectra measured for $\mathrm{CCl}_{3} \mathrm{SCN}$ and $\mathrm{CCl}_{2} \mathrm{FSCN}$ near the $\mathrm{Cl} 2 \mathrm{p}$ region are depicted in Figure 6 . The $\mathrm{Cl} 2 \mathrm{p}$ threshold is

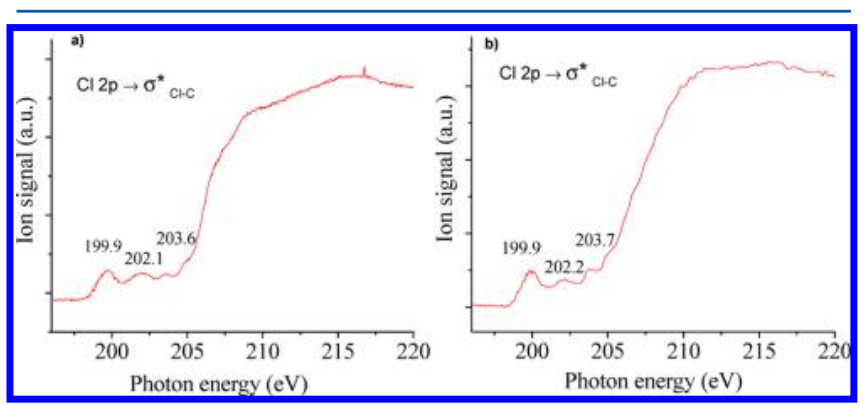

Figure 6. Total ion yield spectra for $\mathrm{CCl}_{3} \mathrm{SCN}$ (a) and $\mathrm{CCl}_{2} \mathrm{FSCN}$ (b) near the $\mathrm{Cl} 2 \mathrm{p}$ edge.

positioned in the region of $210.0 \mathrm{eV}$, in accordance with the values previously reported for similar molecules containing chlorinated groups. ${ }^{13,14,46-52}$ Centered at about 200.0, 202.0, and $204.0 \mathrm{eV}$, three wide and not well resolved bands can be observed in this region. Two of these signals could be attributed to electronic transitions related the spin-orbital split of the $2 \mathrm{p}$ term in the $2 \mathrm{p}_{1 / 2}$ and $2 \mathrm{p}_{3 / 2}$ levels of the excited species toward the $\mathrm{LUMO}+2\left(\sigma^{*} \mathrm{Cl}-\mathrm{C}\right)$ vacant orbital. The prominence of transitions toward $\mathrm{C}-\mathrm{Cl}$ antibonding (vacant) orbitals has been already noted for $\mathrm{Cl} 2 \mathrm{p}$ excited organochlorinated species. ${ }^{53,54}$

3.5. PEPICO Spectra. A number of PEPICO spectra have been registered during this study. The photon energies have been selected using the resonant values detected from the TIY spectra taken into consideration the regions corresponding to both $\mathrm{S} 2 \mathrm{p}$ and $\mathrm{Cl} 2 \mathrm{p}$ levels. It is also typical for this kind of study to have measurements of PEPICO spectra below and above the ionization value, generally 10 and $50 \mathrm{eV}$, respectively. The spectra are achieved by the arrival of only one ion during the period in which the window is open. This process can be due to either a single ionization or multiple ionization processes. In this case, only the lighter and faster ion can be detected. PEPICO spectra for $\mathrm{CCl}_{3} \mathrm{SCN}$ and $\mathrm{CCl}_{2} \mathrm{FSCN}$ are depicted in Figure 7, and the corresponding branching ratios for the main fragment ions are listed in Table 3.

In both compounds, the most abundant ion formed is $\mathrm{Cl}^{+}$ (14-20\% approximately), reaching relative abundance near $25 \%$ at $199.9 \mathrm{eV}$ of energy ( $\mathrm{Cl} 2 \mathrm{p}$ edge). Other noticeable ions evidenced in the spectra with relative abundances between 4 and $13 \%$ are $\mathrm{Cl}_{3} \mathrm{C}^{+} / \mathrm{CCl}_{2} \mathrm{~F}^{+}(\mathrm{m} / z=117 / 101), \mathrm{Cl}_{2} \mathrm{C}^{+}(\mathrm{m} / z=$ $82), \mathrm{ClCS}^{+} / \mathrm{FCS}^{+}(m / z=79 / 63), \mathrm{SCN}^{+}(m / z=58), \mathrm{ClC}^{+} /$ $\mathrm{FC}^{+}(m / z=47 / 31), \mathrm{CS}^{+}(m / z=44), \mathrm{S}^{+}(m / z=32), \mathrm{CN}^{+}(m /$ $z=26), \mathrm{N}^{+}(m / z=14)$, and $\mathrm{C}^{+}(m / z=12)$. Few changes become apparent when the recorded PEPICO spectra obtained at different photon energies are compared. At higher energies by going from the $S 2 p$ to the $\mathrm{Cl} 2 \mathrm{p}$ region an expected atomization process results evident since an increase in the peak intensities corresponding to the lighter ions or fragments $\mathrm{C}^{+}, \mathrm{N}^{+}, \mathrm{S}^{+}, \mathrm{Cl}^{+}$, and $\mathrm{SCN}^{+}$, together with the concomitant decrease in the intensities of the heaviest ions $\mathrm{CCl}_{2} \mathrm{FSCN}^{+}$, $\mathrm{CCl}_{3}{ }^{+}, \mathrm{CCl}_{2} \mathrm{~F}^{+}$, and $\mathrm{CCl}_{2}{ }^{+}$, can be observed. 


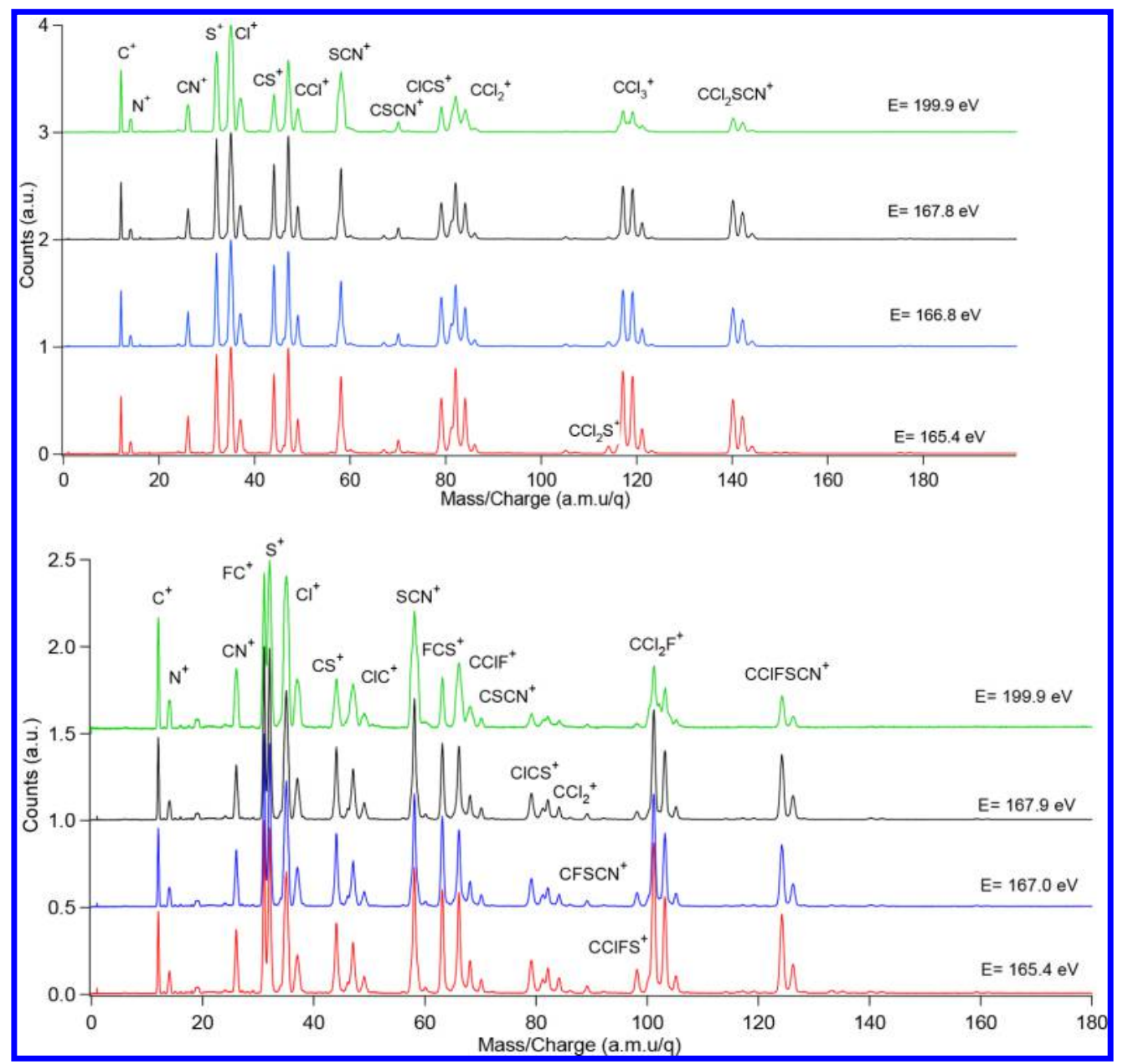

Figure 7. PEPICO spectra of $\mathrm{CCl}_{3} \mathrm{SCN}$ (top panel) and $\mathrm{CCl}_{2} \mathrm{FSCN}$ (bottom panel) at the main resonance values observed in the TIY near the $\mathrm{S} 2 \mathrm{p}$ and $\mathrm{Cl} 2 \mathrm{p}$ edges.

Using the information deduced from the PEPICO peak contour, the kinetic energy release (KER) value can be inferred for the formed ions at the registered photon energies, as shown in Table 3. The $\mathrm{Cl} 2 \mathrm{p}$ region results are interesting since all ions present high KER values. Experimentally, this fact is associated with broad peaks as observed at the higher energies registered in the Figure 7 for both title compounds. This fact can be explained since the decay of core-shell-excited species usually promotes the formation of doubly charged parent ions in several excited states. Subsequently, they could then dissociate, releasing much of their internal energy as kinetic energy of the fragment ions (KER).

Species such as $\mathrm{CCl}_{2} \mathrm{SCN}^{+}(m / z=140)$ and $\mathrm{CClFSCN}^{+}(m /$ $z=124$ ) with relative low KER values can only be derived from the singly charged $\mathrm{CCl}_{3} \mathrm{SCN}$ and $\mathrm{CCl}_{2} \mathrm{FSCN}$ molecules, respectively, since these fragments, taken into account the basis of the PEPICO spectroscopy, must be the lightest in the PEPICO spectra. The loss of neutral fragments (chlorine atom) is similar to that proposed in the valence region (Scheme 2). As shown in Figure 8, panels $\mathrm{b}$ and d, the peak shapes observed for these ions are clearly symmetric.

$$
\begin{aligned}
& \mathrm{CCl}_{3} \mathrm{SCN}^{\bullet+} \rightarrow \mathrm{CCl}_{2} \mathrm{SCN}^{+}+\mathrm{Cl}^{\bullet} \quad(\mathrm{KER}=0.17-0.22 \mathrm{eV}) \\
& \mathrm{CCl}_{2} \mathrm{FSCN}^{\bullet+} \rightarrow \mathrm{CClFSCN}^{+}+\mathrm{Cl}^{\bullet} \quad(\mathrm{KER}=0.19-0.21 \mathrm{eV})
\end{aligned}
$$

The same concept can be applied to the formation of $\mathrm{CCl}_{3}^{+}$ and $\mathrm{CCl}_{2} \mathrm{~F}^{+}$fragments (see Figure 8, panels a and c, respectively). The following simple mechanisms explain the experimental observation:

$$
\begin{aligned}
& \mathrm{CCl}_{3} \mathrm{SCN}^{\bullet+} \rightarrow \mathrm{CCl}_{3}^{+}+\mathrm{SCN}^{\bullet} \quad(\mathrm{KER}=0.18-0.68 \mathrm{eV}) \\
& \mathrm{CCl}_{2} \mathrm{FSCN}^{\bullet+} \rightarrow \mathrm{CCl}_{2} \mathrm{~F}^{+}+\mathrm{SCN}^{\bullet} \quad(\mathrm{KER}=0.19-0.53 \mathrm{eV})
\end{aligned}
$$

Figure 8 depicts also the PEPICO spectra for arriving times corresponding to the $\mathrm{SCN}^{+}(m / z=58)$ ion for both molecules. The $\mathrm{SCN}^{+}$species could be produced from both singly and doubly charged molecular ions. The analysis of the KER distribution is decisive in this case in order to determine the origin of this fragment. From the peak shapes observed in both ranges of energy ( $\mathrm{S} 2 \mathrm{p}$ edge and $\mathrm{Cl} 2 \mathrm{p}$ edge), a clear double KER distribution can be observed. At higher photon energies, the formation of double charged ions is favored and broader peaks appear for this ion in the spectra. This behavior suggests that when the thiocyanates are excited at shallow-core $S 2 p$ and $\mathrm{Cl} 2 \mathrm{p}$ levels, $\mathrm{SCN}^{+}$ions are originated by both single and double charged molecular ions, according to the equations:

$$
\begin{aligned}
& \mathrm{CX}_{3} \mathrm{SCN}^{+} \rightarrow \mathrm{CX}_{3}+\mathrm{SCN}^{+} \\
& \mathrm{CX}_{3} \mathrm{SCN}^{2+} \rightarrow \mathrm{CX}_{3}^{+}+\mathrm{SCN}^{+}
\end{aligned}
$$

3.6. PEPIPICO Spectra. To further determine the ionic dissociation mechanism following the photon absorption, twodimensional PEPIPICO spectra have been also recorded. In this method, correlation between one electron and the two 
Table 3. Branching Ratios (\%) for Fragment Ions Extracted from PEPICO Spectra Taken at Photon Energies around the $\mathrm{S} 2 \mathrm{p}$ and $\mathrm{Cl} 2 \mathrm{p}$ edges for $\mathrm{CCl}_{3} \mathrm{SCN}$ and $\mathrm{CCl}_{2} \mathrm{FSCN}$ Molecules $^{a}$

\begin{tabular}{|c|c|c|c|c|c|}
\hline \multirow[b]{4}{*}{$m / z$} & \multirow[b]{4}{*}{ ion } & \multicolumn{3}{|c|}{$\mathrm{CCl}_{3} \mathrm{SCN}$} & \\
\hline & & \multicolumn{4}{|c|}{ photon energy $(\mathrm{eV})$} \\
\hline & & \multicolumn{3}{|c|}{ S $2 p$} & \multirow{2}{*}{$\begin{array}{l}\mathrm{Cl} 2 \mathrm{p} \\
199.9\end{array}$} \\
\hline & & 165.4 & 166.8 & 167.8 & \\
\hline 12 & $\mathrm{C}^{+}$ & 3.9 & $4.3 / 2.25$ & 4.5 & $6.2 / 3.41$ \\
\hline 14 & $\mathrm{~N}^{+}$ & 1.5 & $1.5 / 5.18$ & 1.5 & $2.2 / 7.11$ \\
\hline 26 & $\mathrm{CN}^{+}$ & 3.5 & $3.7 / 2.15$ & 3.6 & 4.1/3.47 \\
\hline 32 & $\mathrm{~S}^{+}$ & 8.8 & $9.2 / 1.37$ & 9.8 & $11.9 / 2.54$ \\
\hline 35 & $\mathrm{Cl}^{+}$ & 17.2 & $19.6 / 2.61$ & 20.4 & $25.6 / 3.50$ \\
\hline 44 & $\mathrm{CS}^{+}$ & 6.1 & $7.2 / 0.68$ & 6.7 & $4.7 / 1.38$ \\
\hline 47 & $\mathrm{CCl}^{+}$ & 11.9 & $12.5 / 0.82$ & 13.7 & $13.1 / 1.72$ \\
\hline 58 & $\mathrm{SCN}^{+}$ & 7.3 & $6.8 /^{b}$ & 7.4 & $10.3 /^{b}$ \\
\hline 70 & $\mathrm{CSCN}^{+}$ & 1.1 & $1.1 / 0.26$ & 1.0 & $1.1 / 0.41$ \\
\hline 79 & $\mathrm{ClCS}^{+}$ & 5.7 & $4.6 / 0.46$ & 5.5 & $2.7 / 0.53$ \\
\hline 82 & $\mathrm{CCl}_{2}^{+}$ & 11.7 & $11.5 / 1.04$ & 9.2 & $9.8 / 1.73$ \\
\hline 117 & $\mathrm{CCl}_{3}^{+}$ & 12.7 & $10.3 / 0.18$ & 9.5 & $5.8 / 0.68$ \\
\hline 140 & $\mathrm{CCl}_{2} \mathrm{SCN}^{+}$ & 7.1 & $5.9 / 0.17$ & 6.0 & $2.5 / 0.22$ \\
\hline \multicolumn{6}{|c|}{$\mathrm{CCl}_{2} \mathrm{FSCN}$} \\
\hline & & \multicolumn{4}{|c|}{ photon energy $(\mathrm{eV})$} \\
\hline & & \multicolumn{3}{|c|}{ S $2 p$} & $\mathrm{Cl} 2 \mathrm{p}$ \\
\hline$m / z$ & ion & 165.4 & 167.0 & 167.9 & 199.9 \\
\hline 12 & $\mathrm{C}^{+}$ & 4.3 & $4.6 / 2.69$ & 4.8 & $6.2 / 3.83$ \\
\hline 14 & $\mathrm{~N}^{+}$ & 1.9 & $2.0 / 5.74$ & 2.0 & $3.0 / 7.51$ \\
\hline 19 & $\mathrm{~F}^{+}$ & & & & 1.4 \\
\hline 26 & $\mathrm{CN}^{+}$ & 4.3 & $4.4 / 2.16$ & 4.3 & $5.1 / 3.46$ \\
\hline 31 & $\mathrm{CF}^{+}$ & 8.0 & $8.9 / 0.46$ & 9.1 & $7.7 / 1.97$ \\
\hline 32 & $S^{+}$ & 10.2 & $10.9 / 0.80$ & 11.3 & $11.6 / 3.65$ \\
\hline 35 & $\mathrm{Cl}^{+}$ & 14.3 & $16.4 / 2.77$ & 17.1 & $19.0 / 4.62$ \\
\hline 44 & $\mathrm{CS}^{+}$ & 4.7 & $5.2 / 0.83$ & 5.0 & $4.1 / 1.83$ \\
\hline 47 & $\mathrm{CCl}^{+}$ & 5.3 & $5.2 / 1.2$ & 5.6 & $6.4 / 3.01$ \\
\hline 58 & $\mathrm{SCN}^{+}$ & 7.8 & $7.6 /^{b}$ & 8.1 & $9.7 / /^{b}$ \\
\hline 63 & $\mathrm{FCS}^{+}$ & 5.4 & $5.1 / 0.40$ & 4.3 & $2.8 / 0.48$ \\
\hline 66 & $\mathrm{ClCF}^{+}$ & 7.8 & $6.9 / 0.41$ & 6.6 & $7.3 / 1.56$ \\
\hline 70 & $\mathrm{CSCN}^{+}$ & 0.8 & $0.8 / 0.33$ & 0.8 & $1.2 / 0.43$ \\
\hline 79 & $\mathrm{ClCS}^{+}$ & 3.0 & $2.9 / 0.52$ & 2.7 & $2.3 / 0.64$ \\
\hline 82 & $\mathrm{CCl}_{2}^{+}$ & 2.7 & $2.3 / 0.17$ & 2.4 & $2.1 / 0.59$ \\
\hline 98 & $\mathrm{CClFS}^{+}$ & 1.8 & $1.3 / 0.18$ & 0.9 & \\
\hline 101 & $\mathrm{CCl}_{2} \mathrm{~F}^{+}$ & 12.3 & $10.3 / 0.19$ & 9.8 & $7.6 / 0.53$ \\
\hline 124 & $\mathrm{CClFSCN}^{+}$ & 5.2 & $4.7 / 0.19$ & 4.8 & $3.0 / 0.21$ \\
\hline
\end{tabular}

${ }^{a}$ Kinetic energy release values (in $\mathrm{eV}$ ) determined from the spectra at 166.8 and $199.9 \mathrm{eV}$ are given in italics. Contributions of the 35/37 natural isotopologues of $\mathrm{Cl}$ were summed together. Ions with branching ratios lower than $1 \%$ are not listed. ${ }^{b}$ Double KER distribution is observed (see text).

lighter positive ions are observed, enabling the study of the dissociation of double ionized species. Thus, PEPIPICO spectra were registered as in the case of PEPICO at each of the resonant energies values on the $S 2 p$ and $\mathrm{Cl} 2 \mathrm{p}$ regions. Furthermore, the analysis of the PEPIPICO spectra is useful for identifying the dynamic of the fragmentation processes, and the occurrence of two-, three-, ${ }^{22}$ and four-body dissociation mechanisms can be determined. ${ }^{55,56}$

The evaluation of the experimental slopes for coincidence islands in the resonance and off-resonance $S 2 p$ photon energy region evidence that the observed differences in the dissociation mechanisms are less significant. The following discussion will be referred to slopes determined from the PEPIPICO spectrum taken at 166.8 and $167.0 \mathrm{eV}$ photon energies for $\mathrm{CCl}_{3} \mathrm{SCN}$ and $\mathrm{CCl}_{2}$ FSCN species, respectively. The contour plots for coincidence islands between selected pair of ions are shown in Figures S3 and S4 in the Supporting Information.

3.6.1. Dynamics of Fragmentation for the $\mathrm{CCl}_{3} \mathrm{SCN}^{2+}$ Ion. Coincidence between lons with $\mathrm{m} / \mathrm{z}$ Values of $58 \mathrm{amu} / \mathrm{q}$ $\left(\mathrm{SCN}^{+}\right)$and $117 \mathrm{amu} / \mathrm{q}\left(\mathrm{CCl}_{3}^{+}\right)$. This coincidence is observed in the PEPIPICOs as a well-defined and intense island with the natural ${ }^{35} \mathrm{Cl} /{ }^{37} \mathrm{Cl}$ isotope distribution, as can be observed in Figure S3 (panel A) for the spectrum at $166.8 \mathrm{eV}$. A simple fragmentation mechanism involving the rupture of the $\mathrm{C}-\mathrm{S}$ bond is deduced for the experimental coincidence island due to its characteristic parallelogram-like shape and the observed slope of -1.0. A similar behavior has been reported for the $\mathrm{CH}_{3} \mathrm{SCN}$ and $\mathrm{CH}_{2} \mathrm{ClSCN}$ species. ${ }^{13,14}$

$$
\mathrm{CCl}_{3} \mathrm{SCN}^{+2} \rightarrow \mathrm{CCl}_{3}^{+}+\mathrm{SCN}^{+} \quad \alpha=-1.0
$$

Coincidence between lons with $\mathrm{m} / \mathrm{z}$ Values of $58 \mathrm{amu} / \mathrm{q}$ $\left(\mathrm{SCN}^{+}\right)$and $82 \mathrm{amu} / q\left(\mathrm{CCl}_{2}^{+}\right)$. The $\mathrm{SCN}^{+}$and the $\mathrm{CCl}_{2}^{+}$ions coincide also with a slope of -1.0 (Figure S3B). The formation of both charged species and the neutral $\mathrm{Cl}$ atom might be produced by a three-body Coulombic explosion. However, a deferred charge separation mechanism can be postulated due to the observed broadening in the peak shape. This is a three-body reaction involving the loss of a $\mathrm{Cl}$ neutral fragment in the first step and the subsequent formation of the double charged intermediate $\mathrm{CCl}_{2} \mathrm{SCN}^{2+}$ :

$$
\begin{aligned}
& \mathrm{CCl}_{3} \mathrm{SCN}^{+2} \rightarrow \mathrm{CCl}_{2} \mathrm{SCN}^{+2}+\mathrm{Cl} \quad \alpha=-1.0 \\
& \mathrm{CCl}_{2} \mathrm{SCN}^{+2} \rightarrow \mathbf{C C l}_{2}^{+}+\mathbf{S C N}^{+}
\end{aligned}
$$

Coincidence between lons with $\mathrm{m} / \mathrm{z}$ Values of $32 \mathrm{amu} / \mathrm{q}$ $\left(\mathrm{S}^{+}\right)$and $117 \mathrm{amu} / \mathrm{q}\left(\mathrm{CCl}_{3}^{+}\right)$. A probable mechanism for this coincidence could be a three-body secondary decay (SD) since the experimental slope for this island is -1.6 (calculated $\alpha=$ $-1.8)$. This graphic is shown in Figure S3C.

$$
\begin{aligned}
& \mathrm{CCl}_{3} \mathrm{SCN}^{+2} \rightarrow \mathrm{CCl}_{3}^{+}+\mathrm{SCN}^{+} \\
& \mathrm{SCN}^{+} \rightarrow \boldsymbol{S}^{+}+\mathrm{CN}
\end{aligned}
$$

Coincidence between lons with $\mathrm{m} / \mathrm{z}$ Values of $32 \mathrm{amu} / \mathrm{q}$ $\left(\mathrm{S}^{+}\right)$and $82 \mathrm{amu} / \mathrm{q}\left(\mathrm{CCl}_{2}^{+}\right)$. A four-body secondary decay in competition (SDC) represents a reasonable mechanism for this coincidence:

$$
\begin{aligned}
& \mathrm{CCl}_{3} \mathrm{SCN}^{2+} \rightarrow \mathrm{CCl}_{3}^{+}+\mathrm{SCN}^{+} \\
& \mathrm{CCl}_{3}^{+} \rightarrow \mathbf{C C l}_{2}^{+}+\mathrm{Cl} \\
& \mathrm{SCN}^{+} \rightarrow \boldsymbol{S}^{+}+\mathrm{CN}
\end{aligned}
$$

When the kinetic energy release corresponding to the ejection of a neutral fragment is ignored, a slope of -1.2 can be calculated in the frame of a SDC mechanism. This value agrees with the determined experimentally of $\alpha=-1.3$, as shown in Figure S3D.

3.6.2. Dynamics of Fragmentation for the $\mathrm{CCl}_{2} \mathrm{FSCN}^{2+}$ ion. Coincidence between lons with $\mathrm{m} / \mathrm{z}$ Values of $58 \mathrm{amu} / \mathrm{q}$ $\left(\mathrm{SCN}^{+}\right)$and $101 \mathrm{amu} / \mathrm{q}\left(\mathrm{CCl}_{2} \mathrm{~F}^{+}\right)$. In coincidence with the halomethyl-thiocyanate family, the most abundant photofragmentation channels of core-excited $\mathrm{CCl}_{2} \mathrm{FSCN}$ is the rupture of $\mathrm{C}-\mathrm{S}$ single bond from double charge molecular ion to form $\mathrm{SCN}^{+}$and $\mathrm{CCl}_{2} \mathrm{~F}^{+}$species. This island of 


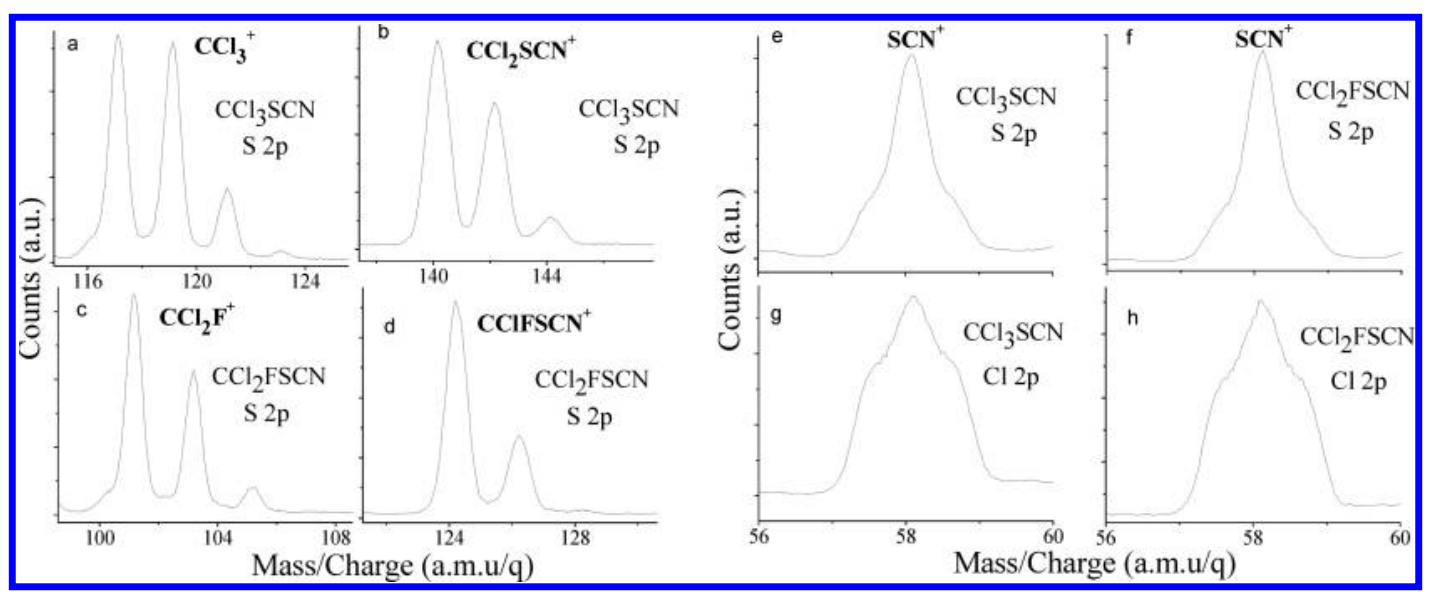

Figure 8. (a, b) Enlargement of the $\mathrm{m} / z$ region corresponding to $\mathrm{CCl}_{3}{ }^{+}$and $\mathrm{CCl}_{2} \mathrm{SCN}^{+}$ions of the PEPICO spectrum of $\mathrm{CCl}_{3} \mathrm{SCN}$ at $166.8 \mathrm{eV}$ of energy. (c, d) Enlargement of the $\mathrm{m} / z$ region corresponding to $\mathrm{CCl}_{2} \mathrm{~F}^{+}$and $\mathrm{CClFSCN}^{+}$ions of the PEPICO spectrum of $\mathrm{CCl}_{2} \mathrm{FSCN}$ at $167.0 \mathrm{eV}$ of energy. (e, g) Enlargement of the $\mathrm{m} / z$ region corresponding to $\mathrm{SCN}^{+}$ion of the PEPICO spectrum of $\mathrm{CCl}_{3} \mathrm{SCN}$ at $166.8 \mathrm{eV}$ (S $2 \mathrm{p}$ edge) and 199.9 $\mathrm{eV}\left(\mathrm{Cl} 2 \mathrm{p}\right.$ ) of energy. (f, h). Enlargement of the $\mathrm{m} / z$ region correspond to $\mathrm{SCN}^{+}$ion of the PEPICO spectrum of $\mathrm{CCl}_{2} \mathrm{FSCN}_{\text {at }} 167.0 \mathrm{eV}(\mathrm{S} 2 \mathrm{p}$ edge) and $199.9 \mathrm{eV}(\mathrm{Cl} \mathrm{2p})$ of energy.

coincidence is one of the most intense and can be observed with a parallelogram-like shape and a slope of -1.0 (see Supporting Information Figure S4A).

$$
\mathrm{CCl}_{2} \mathrm{FSCN}^{+2} \rightarrow \mathbf{C C l}_{2} \boldsymbol{F}^{+}+\mathbf{S C N}^{+} \quad \alpha=-1.0
$$

Coincidence between lons with $\mathrm{m} / \mathrm{z}$ Values of $32 \mathrm{amu} / \mathrm{q}$ $\left(\mathrm{S}^{+}\right)$and $101 \mathrm{amu} / \mathrm{q}\left(\mathrm{CCl}_{2} \mathrm{~F}^{+}\right)$. In Figure S4B, the coincidence between these ions has been observed with the slope of -1.4. The occurrence of the three-body secondary decay (SD) mechanism, with an calculated slope of -1.8 can be the origin of this coincidence island.

$$
\begin{aligned}
& \mathrm{CCl}_{2} \mathrm{FSCN}^{+2} \rightarrow \mathrm{CCl}_{2} \boldsymbol{F}^{+}+\mathrm{SCN}^{+} \\
& \mathrm{SCN}^{+} \rightarrow \boldsymbol{S}^{+}+\mathrm{CN}
\end{aligned}
$$

Coincidence between lons with $\mathrm{m} / \mathrm{z}$ Values of $32 \mathrm{amu} / \mathrm{q}$ $\left(\mathrm{S}^{+}\right)$and $66 \mathrm{amu} / \mathrm{q}\left(\mathrm{CCIF}^{+}\right)$. A coincidence island with an experimental slope of -1.2 , as shown in Figure S4C, indicates that the four-body secondary decay in competition (SDC) can be a probable mechanism for this coincidence since its calculated slope is -1.4 , if the kinetic energy release corresponding to the ejection of the neutral fragments is neglected.

$$
\begin{aligned}
& \mathrm{CCl}_{2} \mathrm{FSCN}^{+2} \rightarrow \mathrm{CCl}_{2} \mathrm{~F}^{+}+\mathrm{SCN}^{+} \\
& \mathrm{SCN}^{+} \rightarrow \boldsymbol{S}^{+}+\mathrm{CN} \\
& \mathrm{CCl}_{2} \mathrm{~F}^{+} \rightarrow \mathbf{C C l F}^{+}+\mathrm{Cl}
\end{aligned}
$$

\section{CONCLUSIONS}

An exhaustive study of electronic properties of the $\mathrm{CCl}_{3} \mathrm{SCN}$ and $\mathrm{CCl}_{2} \mathrm{FSCN}$ molecules in the gas phase following continuum valence and shallow-core ( $\mathrm{S} 2 \mathrm{p}$ and $\mathrm{Cl} 2 \mathrm{p}$ ) excitations has been performed using multicoincidence techniques based of time-of-flight mass spectrometry and synchrotron radiation in combination with photoelectron spectroscopy. PES spectra of both molecules are analyzed, and the valence electronic structure determined. HOMO corresponds to an $\mathrm{n}_{\pi}(S)$ lone pair electrons, characterized like a well-defined band in the photoelectron spectra. A dependency of the vertical ionization energy with the electronegativity of the $-\mathrm{CX}_{3}(\mathrm{X}=\mathrm{H}, \mathrm{Cl}, \mathrm{F})$ group have been observed for the $\mathrm{CX}_{3} \mathrm{SCN}$ species.

TIY spectra of the title molecules in the $\mathrm{S} 2 \mathrm{p}$ and $\mathrm{Cl} 2 \mathrm{p}$ levels were recorded. The spectra for these species are dominated by a group of well-defined signals between 164.0 and $169.0 \mathrm{eV}$ of energy, and these resonant transitions are due to dipole allowed transitions that involve electronic transitions from an atomic $2 p$ to an antibonding molecular orbital.

The ionic fragmentation in both valence and shallow-core regions were analyzed with the PEPICO and PEPIPICO techniques. Dissociation mechanisms have been proposed in order to explain the ionic fragmentation decay for single- and double-charged species. In the valence region, very simple PEPICO spectra are obtained. The single charged molecular ion is observed with low intensity, whereas the main photodissociation channel is produced for the rupture of the sulfur-carbon single bond, leading to the formation of $\mathrm{CCl}_{2} \mathrm{X}^{+}$ ions $(\mathrm{X}=\mathrm{Cl}$ or $\mathrm{F})$. Furthermore, the analysis of the PEPIPICO spectra has been used to identify the dissociation mechanisms for doubly charged parent ions. Fragmentation processes leading to the formation of $\mathrm{CX}_{3}^{+}$and $\mathrm{SCN}^{+}$ions from $\mathrm{CX}_{3} \mathrm{SCN}^{+2}$ dominate the dissociation of halomethyl-thiocyanates excited at the $S 2 p$ levels. Also, the three-body secondary decay (SD) mechanism is one of the main photodissociation channels observed in both molecules, which leads to the formation of $\mathrm{S}^{+}$and $\mathrm{CX}_{3}{ }^{+}$ions in the coincidence island. In both cases, the experimental slopes have been in agreement with the calculated ones.

\section{ASSOCIATED CONTENT}

\section{Supporting Information}

The Supporting Information is available free of charge on the ACS Publications website at DOI: 10.1021/acs.jpca.7b08395.

Correlation diagram of the ionization potential of $\mathrm{CX}_{3} \mathrm{SCN}$ molecules; characters of the four lowest unoccupied orbitals $\mathrm{CCl}_{3} \mathrm{SCN}$ and $\mathrm{CCl}_{2} \mathrm{FSCN}$; contour plot for the main coincidence island observed in the PEPIPICO spectra of $\mathrm{CCl}_{3} \mathrm{SCN}$ and $\mathrm{CCl}_{2} \mathrm{FSCN}$ (PDF) 


\section{AUTHOR INFORMATION}

\section{Corresponding Authors}

*Tel: +54-221-4454393. E-mail: erben@quimica.unlp.edu.ar. *E-mail: carlosdv@quimica.unlp.edu.ar.

\section{ORCID}

Carlos O. Della Védova: 0000-0002-2439-2147

Maofa Ge: 0000-0002-1771-9359

Mauricio F. Erben: 0000-0001-8467-2784

\section{Notes}

The authors declare no competing financial interest.

\section{ACKNOWLEDGMENTS}

This work has been largely supported by the Brazilian Synchrotron Light Source (LNLS). The authors wish to thank the TGM beamline staffs for their assistance throughout the experiments (proposals D05A-TGM-8230). They also are indebted to the ANPCyT, Agencia Nacional de Promoción Científica y Tecnológica (PICT 2130), Consejo Nacional de Investigaciones Cientificas y Técnicas (CONICET), and the Facultad de Ciencias Exactas, Universidad Nacional de La Plata for financial support. C.O.D.V., M.F.E., and R.M.R. acknowledge CONICET/ACRPC for the travel support to visit the Institute of Chemistry of the Chinese Academy of Science in Beijing.

\section{DEDICATION}

Dedicated to Prof. Dr. Rüdiger Mews on occasion of his 75 birthday.

\section{REFERENCES}

(1) Erian, A. W.; Sherif, S. M. The Chemistry of Thiocyanic Esters. Tetrahedron 1999, 55, 7957-8024.

(2) Sharma, S. Isothiocyanates in Heterocyclic Synthesis. I. Sulfur Chem. 1989, 8, 327-454.

(3) Magnus, P. D. Recent Developments in Sulfone Chemistry. Tetrahedron 1977, 33, 2019-2045.

(4) Muthusubramanian, L.; Mitra, R. B.; Rajkumar, S.; Sundara Rao, V. S. Convenient Synthesis of (Thiocyanomethyl)-Thio Heteroaromatics as Antifungal Agents. I. Chem. Technol. Biotechnol. 1998, 72, 164-168.

(5) Muthusubramanian, L.; Mitra, R. B. Efficient Synthesis of Chloromethyl thiocyanate for Use in Fungicide Production. I. Soc Leather Technol. Chem. 2003, 87, 115-115.

(6) Olin, J. F.; Mich, G. I. Trichloro Methyl Thiocyanate and Process for Preparing Same. U.S. Patent 2,650,240, 1953.

(7) Lukes, G. E. Method for Controlling Microorganisms and Nematodes. U.S. Patent 3,361,621, 1968.

(8) Coyanis, E. M.; Rubio, R. E.; Gobbato, K. I.; Mack, H. G.; Della Védova, C. O. Vibrational, Conformational and Theoretical Studies of Dichlorofluoromethyl thiocyanate, $\mathrm{CCl}_{2} \mathrm{FSCN}$. I. Mol. Struct. 1995, $344,45-51$.

(9) Ulic, S. E.; Di Napoli, F.; Hermann, A.; Mack, H. G.; Della Védova, C. O. Vibrational Spectra and ab initio Calculations on Trichloromethanesulphenyl Cyanide, $\mathrm{CCl}_{3} \mathrm{SCN}$. L. Raman Spectrosc. 2000, 31, 909-913.

(10) Berrueta Martínez, Y.; Rodríguez Pirani, L. S.; Erben, M. F.; Boese, R.; Reuter, C. G.; Vishnevskiy, Y. V.; Mitzel, N. W.; Della Védova, C. O. Structures of Trichloromethyl Thiocyanate, $\mathrm{CCl}_{3} \mathrm{SCN}$, in Gaseous and Crystalline State. ChemPhysChem 2016, 17, 14631467.

(11) Martínez, Y. B.; Rodríguez Pirani, L. S.; Erben, M. F.; Boese, R.; Reuter, C. G.; Vishnevskiy, Y. V.; Mitzel, N. W.; Della Védova, C. O. Gas and Crystal Structures of $\mathrm{CCl}_{2} \mathrm{FSCN}$. I. Mol. Struct. 2017, 1132, 175-180.
(12) Hitchcock, A. P.; Tronc, M.; Modelli, A. Electron Transmission and Inner-Shell Electron Energy Loss Spectroscopy of Acetonitrile, Isocyanomethane, Methyl thiocyanate, and Isothiocyanatomethane. I. Phvs. Chem. 1989, 93, 3068-3077.

(13) Cortés, E.; Erben, M. F.; Geronés, M.; Romano, R. M.; Della Védova, C. O. Dissociative Photoionization of Methyl Thiocyanate, $\mathrm{CH}_{3} \mathrm{SCN}$, in the Proximity of the Sulfur $2 \mathrm{p}$ Edge. I. Phys. Chem. A 2009, 113, 564-572.

(14) Rodríguez Pirani, L. S.; Geronés, M.; Della Védova, C. O.; Romano, R. M.; Fantoni, A.; Cavasso-Filho, R.; Ma, C.; Ge, M.; Erben, M. F. Electronic Properties and Dissociative Photoionization of Thiocyanates. Part II. Valence and Shallow-Core (Sulfur and Chlorine 2p) Regions of Chloromethyl Thiocyanate, $\mathrm{CH}_{2} \mathrm{ClSCN}$. I. Phvs. Chem. A 2012, 116, 231-241.

(15) Lira, A. C.; Rodrigues, A. R. D.; Rosa, A.; Goncalves da Silva, C. E. T.; Pardine, C.; Scorzato, C.; Wisnivesky, D.; Rafael, F.; Franco, G. S.; Tosin, G.et al. In First Year Operation of the Brazilian Source; European Particle Accelerator Conference, Stockholm, 1998, EPAC.

(16) Fonseca, P. de T.; Pacheco, J. G.; d'A Samogin, E.; de Castro, A. R. B. Vacuum Ultraviolet Beam Lines at Laboratório Nacional de Luz Sincrotron, the Brazilian Synchrotron Source. Rev. Sci. Instrum. 1992, $63,1256-1259$.

(17) Burmeister, F.; Coutinho, L. H.; Marinho, R. R. T.; Homem, M. G. P.; de Morais, M. A. A.; Mocellin, A.; Björneholm, O.; Sorensen, S. L.; Fonseca, P. T.; Lindgren, A.; et al. Description and Performance of an Electron-Ion Coincidence TOF Spectrometer Used at the Brazilian Synchrotron Facility LNLS. I.Electron Spectrosc. Relat. Phenom. 2010, $180,6-13$.

(18) Kivimäki, A.; Ruiz, J. Á.; Erman, P.; Hatherly, P.; García, E. M.; Rachlew, E.; Riu, J. R. I.; Stankiewicz, M. An Energy Resolved Electron-Ion Coincidence Study Near the S 2p Thresholds of the $\mathrm{SF}_{6}$ Molecule. I. Phvs. B: At., Mol. Opt. Phvs. 2003, 36, 781-791.

(19) Filho, R. L. C.; Homem, M. G. P.; Landers, R.; Naves de Brito, A. Advances on the Brazilian Toroidal Grating Monochromator (TGM) Beamline. I. Electron Spectrosc. Relat. Phenom. 2005, 144-147, $1125-1127$

(20) Cavasso Filho, R. L.; Lago, A. F.; Homem, M. G. P.; Pilling, S.; Naves de Brito, A. Delivering High-Purity Vacuum Ultraviolet Photons at the Brazilian Toroidal Grating Monochromator (TGM) Beamline. I. Electron Spectrosc. Relat. Phenom. 2007, 156-158, 168-171.

(21) Cavasso Filho, R. L.; Homen, M. G. P.; Fonseca, P. T.; Naves de Brito, A. A Synchrotron Beamline for Delivering High Purity Vacuum Ultraviolet Photons. Rev. Sci. Instrum. 2007, 78, 115104-115108.

(22) Frasinski, L. J.; Stankiewicz, M.; Randall, K. J.; Hatherly, P. A.; Codling, K. Dissociative Photoionisation of Molecules Probed by Triple Coincidence; Double Time-of-Flight Techniques. I.Phvs. B: At. Mol. Phvs. 1986, 19, L819-L824.

(23) Eland, J. H. D.; Wort, F. S.; Royds, R. N. A Photoelectron-IonIon Triple Coincidence Technique for the Study of Double Photoionization and its Consequences. I. Electron Spectrosc. Relat. Phenom. 1986, 41, 297-309.

(24) Naves de Brito, A.; Feifel, R.; Mocellin, A.; Machado, A. B.; Sundin, S.; Hjelte, I.; Sorensen, S. L.; Björneholm, O. Femtosecond Dissociation Dynamics of Core-Excited Molecular Water. Chem. Phvs. Lett. 1999, 309, 377-385.

(25) Laskin, J.; Lifshitz, C. Kinetic Energy Release Distributions in Mass Spectrometry. L. Mass Spectrom. 2001, 36, 459-478.

(26) Simon, M.; LeBrun, T.; Morin, P.; Lavollée, M.; Maréchal, J. L. A Photoelectron-Ion Multiple Coincidence Technique Applied to Core Ionization of Molecules. Nucl. Instrum. Methods Phvs. Res., Sect. B 1991, 62, 167-174.

(27) Santos, A. C. F.; Lucas, C. A.; de Souza, G. G. B. Dissociative Photoionization of $\mathrm{SiF}_{4}$ around the Si 2p Edge: A New TOFMS Study with Improved Mass Resolution. I. Electron Spectrosc. Relat. Phenom. 2001, 114-116, 115-121.

(28) Li, Y.; Zeng, X.; Sun, Q.; Li, H.; Ge, M.; Wang, D. Electronic Structure of $\mathrm{H}_{2} \mathrm{CS}_{3}$ and $\mathrm{H}_{2} \mathrm{CS}_{4}$ : An Experimental and Theoretical Study. Spectrochim. Acta. Part A 2007, 66, 1261-1266. 
(29) Zeng, X.; Yao, L.; Wang, W.; Liu, F.; Sun, Q.; Ge, M.; Sun, Z.; Zhang, J.; Wang, D. Electronic Structures of Acyl Nitrites and Nitrates. Spectrochim. Acta. Part A 2006, 64, 949-955.

(30) Iriarte, A. G.; Erben, M. F.; Gholivand, K.; Jios, J. L.; Ulic, S. E.; Della Védova, C. O. [Chloro(difluoro)acetyl]phosphoramidic Acid Dichloride $\mathrm{ClF}_{2} \mathrm{CC}(\mathrm{O}) \mathrm{NHP}(\mathrm{O}) \mathrm{Cl}_{2}$, Synthesis, Vibrational and NMR

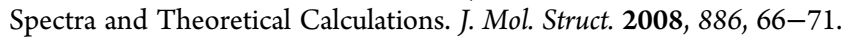

(31) Frisch, M. J.; Trucks, G. W.; Schlegel, H. B.; Scuseria, G. E.; Robb, M. A.; Cheeseman, J. R.; Montgomery, J. A., Jr.; Vreven, T.; Kudin, K. N.; Burant, J. C. et al. Gaussian 03, revision B.04; Gaussian, Inc.: Pittsburgh, PA, 2003.

(32) Brintzinger, H.; Pfannstiel, K.; Koddebusch, H.; Kling, K.-E. Über Alkylschwefelchloride und Halogenalkylschwefelverbindungen. Chem. Ber. 1950, 83, 87-90.

(33) Yarovenko, N. N.; Motornyi, S. P.; Kirenskaya, L. I. Fluoroalkyl Thiocyanates, Isothiocyanates, and Carbylamino Halides. Zh. Obshch. Khim. 1959, 29, 3789-3791.

(34) Deleuze, M. S. Valence One-Electron and Shake-Up Ionisation Bands of Polycyclic Aromatic Hydrocarbons. IV. The Dibenzanthracene Species. Chem. Phvs. 2006, 329, 22-38.

(35) Morini, F.; Knippenberg, S.; Deleuze, M. S.; Hajgato, B. Quantum Chemical Study of Conformational Fingerprints in the Photoelectron Spectra and (e, 2e) Electron Momentum Distributions of n-Hexane. I. Phvs. Chem. A 2010, 114, 4400-4417.

(36) Andreocci, M. V.; Bossa, M.; Furlani, C.; Piancastelli, M. N.; Cauletti, C.; Tarantelli, T. Ultraviolet Photoelectron Spectroscopic Investigation of Electronic Structure of some Organic Thio- and Isothio-cyanates and their Selenium Analogues. I. Chem. Soc., Faradav Trans. 2 1979, 75, 105-112.

(37) Pasinszki, T.; Veszprémi, T.; Fehér, M.; Kovac, B.; Klasinc, L.; Mcglynn, S. P. The Photoelectron Spectra of Methyl Pseudohalides. Int. I. Quantum Chem. 1992, 44, 443-453.

(38) Neijzen, B. J. M.; De Lange, C. A. Photoelectron Spectroscopy of some Thiocyanates, Isocyanates and Isothiocyanates. I. Electron Spectrosc. Relat. Phenom. 1980, 18, 179-188.

(39) Sullivan, J. F.; Heusel, H. L.; Durig, J. R. Infrared and Raman Spectra of Methyl Thiocyanate and Conformations of some Alkyl Thiocyanates and Isothiocyanates. I. Mol. Struct. 1984, 115, 391-396.

(40) Pauling, L. The Nature of the Chemical Bond. IV. The Energy of Single Bonds and the Relative Electronegativity of Atoms. I. Am. Chem. Soc. 1932, 54, 3570-3582.

(41) Parr, R. G.; Pearson, R. G. Absolute Hardness: Companion Parameter to Absolute Electronegativity. I. Am. Chem. Soc. 1983, 105, $7512-7516$.

(42) Politzer, P. A Relationship between the Charge Capacity and the Hardness of Neutral Atoms and Groups. I. Chem. Phys. 1987, 86, 1072-1073.

(43) Politzer, P.; Huheey, J. E.; Murray, J. S.; Grodzicki, M. Electronegativity and the Concept of Charge Capacity. I. Mol. Struct.: THEOCHEM 1992, 259, 99-120.

(44) Thomas, T. D.; Saethre, L. J.; Borve, K. J.; Bozek, J. D.; Huttula, M.; Kukk, E. Carbon 1s Photoelectron Spectroscopy of Halomethanes. Effects of Electronegativity, Hardness, Charge Distribution, and Relaxation. I. Phvs. Chem. A 2004, 108, 4983-4990.

(45) Nenner, I.; Beswick, J. A. Molecular Photodissociation and Photoionization. In Handbook on Sunchrotron Radiation; Marr, G. V., Ed.; Elsevier Science Publishers: Amsterdam, 1987; Vol. 2, pp 355462.

(46) Thissen, R.; Simon, M.; Hubin-Franskin, M. J. Fragmentation of Methyl Chloride Photoexcited near Cl (2p) by Mass Spectrometry. $\underline{I}$ Chem. Phys. 1994, 101, 7548-7553.

(47) Fournier, P. G.; Comtet, G.; Fournier, J.; Svensson, S.; Karlsson, L.; Keane, M. P.; Naves de Brito, A. Double-Ionization Energies of $\mathrm{CCl}_{4}$ by Double-Charge-Transfer and X-Ray Auger-Electron Spectroscopies. Phvs. Rev. A: At., Mol., Opt. Phvs. 1989, 40, 163-170.

(48) Rodríguez Pirani, L. S.; Erben, M. F.; Geronés, M.; Ma, C.; Ge, M.; Romano, R. M.; Cavasso Filho, R. L.; Della Védova, C. O. Outermost and Inner-Shell Electronic Properties of $\mathrm{ClC}(\mathrm{O}) \mathrm{SCH}_{2} \mathrm{CH}_{3}$
Studied Using HeI Photoelectron Spectroscopy and Synchrotron Radiation. I. Phys. Chem. A 2011, 115, 5307-5318.

(49) Kokkonen, E.; Vapa, M.; Bucar, K.; Jankala, K.; Cao, W.; Zitnik, M.; Huttula, M. Formation of Stable $\mathrm{HCl}^{+}$Following Resonant Auger Decay in $\mathrm{CH}_{3} \mathrm{Cl}$. Phvs. Rev. A: At. Mol. Opt. Phvs. 2016, 94, 033409.

(50) Alcantara, K. F.; Gomes, A. H. A.; Wolff, W.; Sigaud, L.; Santos, A. C. F. Strong Electronic Selectivity in the Shallow Core Excitation of the $\mathrm{CH}_{2} \mathrm{Cl}_{2}$ Molecule. I. Phvs. Chem. A 2015, 119, 8822-8831.

(51) Lu, K. T.; Chen, J. M.; Lee, J. M.; Haw, S. C.; Chen, S. A.; Liang, Y. C.; Chen, S. W. State-Selective Enhanced Production of Positive Ions and Excited Neutral Fragments of Gaseous $\mathrm{CH}_{2} \mathrm{Cl}_{2}$ following $\mathrm{Cl}$ 2p Core-Level Photoexcitation. Phvs. Rev. A: At. Mol. Opt. Phvs. 2010, $82,033421$.

(52) Cortes, E.; Della Védova, C. O.; Geronés, M.; Romano, R. M.; Erben, M. F. Perchloromethyl Mercaptan, $\mathrm{CCl}_{3} \mathrm{SCl}$, Excited with Synchrotron Radiation in the Proximity of the Sulfur and Chlorine $2 p$ Edges: Dissociative Photoionization of Highly Halogenated Species. I. Phvs. Chem. A 2009, 113, 9624-9632.

(53) Eland, J. H. D. The Dynamics of Three-Body Dissociations of Dications Studied by the Triple Coincidence Technique PEPIPICO. Mol. Phys. 1987, 61, 725-745.

(54) Simon, M.; Lebrun, T.; Martins, R.; de Souza, G. G. B.; Nenner, I.; Lavollee, M.; Morin, P. Multicoincidence Mass Spectrometry Applied to Hexamethyldisilane Excited Around the Silicon 2p Edge. I. Phvs. Chem. 1993, 97, 5228-5237.

(55) Kukk, E.; Kooser, K.; Ha, D. T.; Granroth, S.; Nommiste, E. VUV-Induced Dissociation of Methylchlorosilanes, Studied by Electron-Ion Coincidence Spectroscopy. L. Phvs. B: At., Mol. Opt. Phys. 2010, 43 (6), 065103.

(56) Erben, M. F.; Geronés, M.; Romano, R. M.; Della Védova, C. O. Dissociative Photoionization of Methoxycarbonylsulfenyl Chloride, $\mathrm{CH}_{3} \mathrm{OC}(\mathrm{O}) \mathrm{SCl}$, Following Sulfur $2 \mathrm{p}$, Chlorine $2 \mathrm{p}$, and Oxygen 1s Excitations. I. Phvs. Chem. A 2007, 111, 8062-8071. 